\title{
The Biochemical Basis of Autistic Behavior and Pathology
}

\author{
Dayan Goodenowe and Elodie Pastural \\ Phenomenome Discoveries Inc. \\ Canada
}

\section{Introduction}

Autism and autism spectrum disorders (ASD) are diseases which are characterized by physical (neurological function and pathology) and behavioral (social interaction) abnormalities that are most commonly diagnosed in children (predominately males) between the ages of 2 and 10 years. Autism is a neurodevelopmental disorder. In autism the Central Nervous System (CNS) cells preferentially affected are the GABAergic Purkinje neurons of the cerebellum. However unlike classical neurodegenerative diseases, in autism, progressive decline is uncommon and there is a concomitant superimposition of neuronal hypersensitivity. This apparent contradiction can be best explained by metabolic abnormalities which have differing effects on specific cell types. Identifying the root of these pleiotropic events has been a topic of intense investigation. From a biochemical perspective, the preponderance of evidence implicates the breakdown of mitochondrial function. From a genetics perspective, genetic mutations targeting mitochondrial function collectively account for more than $10 \%$ of all cases, by far the largest single site genetic contribution. However, despite the evidence implicating impaired mitochondrial function, the extramitochondrial biochemical implications and consequences of an impaired mitochondrial system have not been thoroughly investigated. The following chapter outlines the causes and implications of mitochondrial impairment in autism.

\section{Overview of mitochondrial dysfunction in ASD}

Mitochondrial dysfunction in autism has been implicated by several research groups [1-3]. Elevated plasma lactate, a commonly used indicator of mitochondrial dysfunction, has been observed to present in 20 [4] to 40 percent of ASD subjects [5]. Levels of carnitine, the required fatty acid carrier from the cytosol to the mitochondria, have been reported to be low in ASD subjects' serum [6]. The activity of the mitochondrial electron transport chain (ETC), complexes I and III, has been reported to be decreased [7-9]. Glutathione, the key intramitochondrial reactive oxygen species (ROS) neutralizer, is decreased in ASD [2,10-13]. In addition, lipid peroxidation, a down-stream effect of reduced ROS deactivation, is increased in autistic children [14,15]. Extra-mitochondrial processing of palmitate, the key energy source for mitochondria, was observed to be universally increased in ASD [2].

Subjects with definite mitochondrial disease (according to the criteria defined by [16]) have a higher occurrence of autism than expected by chance in the average population [1], 
especially of regressive autism [17]. Stressors such as fever can lead to the appearance of autistic phenotypic traits in individuals with mitochondrial disease [17]. Since neurodegeneration is a feature of mitochondrial disease, Richard Haas hypothesized that ASD subjects children who undergo regression and/or with symptoms of multisystem disorders are the populations with the highest mitochondrial disease occurrence [1].

Despite tremendous efforts dedicated to the identification of loci associated to autism susceptibility, the numbers of genes and genomic regions involved in ASD families can still not account for the majority of autism cases, with an estimated $10 \%$ to $20 \%$ of all ASD explained by genetic defects [18]. However the occurrence of genetic impairments in mitochondrial genome and, as importantly, in the nuclear DNA coding for the estimated 1,500 mitochondrial proteins, represents a high fraction of this estimate. A study on a Portuguese autism population estimated that as high as $7 \%$ of autistic cases could be attributed to mitochondrial respiratory chain disorders, suggesting that this might be one of the most common disorders associated with autism, especially since not all of the children had been tested for these disorders [19]. Anecdotally, a study on Copy Number Variations reported a copy number gain in the SUCLG2 gene encoding the beta subunit of succinylCoA synthetase ligase, involved in the tricarboxylic acid (TCA) cycle, and in NDUFA11 and ATP5], both involved in oxidative phosphorylation, in three autistic patients [20]. In addition, many linkage analyses pointed to chromosomal regions that contain mitochondria- related genes. At least two studies reported an association between autism and SLC25A12 gene, which encodes the mitochondrial aspartate-glutamate carrier AGC1 $[21,22]$ and whose expression has been shown to be up-regulated in autistic prefrontal cortex [23]; recombinant expression of $S L C 25 A 12$ had been reported to increase mitochondrial metabolism [24]. One of the most commonly identified abnormalities in ASD, the inverted duplication of chromosome 15q11-q13, displayed mitochondrial dysfunction, with mitochondrial proliferation, partial deficiency of respiratory complex III, and moderate acid lactosis in two initially studied autistic patients [25].

Conversely, mitochondrial DNA mutations have been associated to autistic features [8]. Mitochondrial encephalopathy with lactic acidosis and stroke-like episodes (MELAS) is frequently caused by the A3243G mutation in the mitochondrial tRNALeu gene and has been associated to autistic clinical traits [8]; another mutation of the mitochondrial genome, A3260G, usually associated with cardiomyopathy and myopathy, has been recently reported to be also associated to MELAS and autism [26]. Mitochondrial DNA depletion syndrome (MDS) is characterized by a reduction of the mtDNA copy number in affected tissues. The same mitochondrial mutation A3243G has been identified in autistic children with MDS [8].

Mitochondrial DNA mutations may be far more frequent in ASD than anticipated, with a very interesting study on neonatal cord blood samples showing a frequency of $1 / 200$ of common point mutations in mitochondrial DNA [27]; the authors state that "at least one in 200 healthy humans harbors a pathogenic mtDNA mutation that potentially causes disease in the offspring of female carriers" [27]. The offspring of the transmitting females would indeed inherit some of the mutant mitochondria by heteroplasmy.

The contribution of environmental factors to the elevation of autism prevalence has now been clearly established [28]. Some mechanisms underlying these environmental toxic insults have been identified and largely point to mitochondrial dysfunction. One of the most detailed examples is propionic acid, by-product of Clostridium Difficile and now a common 
food preservative [29]. Propionate infused rats are an appropriate animal model of autism not only because of their very similar behaviour to autistic children's but also because of their similar biochemical profiles [30]; for instance, carnitine levels and acyl-carnitine levels are respectively lower and higher in the brain of rats infused intraventricularly with propionate than with PBS [30]. Oxidative stress is increased in the infused rats' brain, which according to the authors may lead to mitochondrial failure, or alternatively, is a result of mitochondrial failure induced by propionate [29]. Among the anticonvulsant drugs whose prenatal exposure has been associated to ASD development, valproate sodium seems to present the highest risk with 9\% of ASD or Asperger syndrome diagnoses among the exposed fetuses as reported in a Scottish study [31]. Valproic acid (VPA) is a well-known carnitine inhibitor, with a mechanism of action involving the TCA cycle component aketoglutarate [32].

It is also tempting to associate the increase in autism prevalence and the expansion of microwave radiation sources in our environment. Early in the eighties it was already shown that rat brain exposure to microwave radiation inhibited mitochondrial electron transport chain function, which resulted in decreased ATP and creatine phosphate levels [33]. Particulate matters from air or water pollution, which are now commonly found in our environment, have been shown to induce microglial activation as reviewed by Block and Calderón-Garcidueñas [34]. Microgliosis is a critical process in neurodegenerative disorders but also and as importantly in ASD [35]. Examples of particulate matters include manufactured aluminum oxide particles, the treatment of which alters mitochondrial potential in human brain microvascular endothelial cells [36], or the pesticide rotenone, which inhibits the ETC complex I and deprives cells of ATP, although not directly inducing microglial activation [37].

Biochemical abnormalities in autism are the norm, not the exception. Genetic abnormalities in mitochondrial processes are the most prevalent in ASD and are likely underestimated, mainly because of poor testing. The list of environmental toxicants clearly associated to ASD is expected to be growing as mitochondrial toxicology is a rapidly emerging field [38]. Biochemical, genetic and environmental data in ASD all point to a very likely role of mitochondria dysfunction in the aetiology of autism, or at least as an autism phenotype [39]. The causes and the effects of these abnormalities are topics of heated discussion within the research community. The focus of this chapter is to describe in greater detail the intra and intercellular role of mitochondria and the consequences of impaired mitochondrial function.

\section{Glutamate, mitochondrial toxicity and selective autistic neuropathology}

Reduced cerebellar Purkinje neuron density is the key neuropathological observation in autism $[40,41]$. Purkinje neurons are glutamate receiving (from excitatory climbing fibers) and GABA transmitting (to the deep cerebellar nuclei) neurons. Purkinje neurons coexist with specialized astrocytes (Bergman glia), which protect the neurons. Subjects with ASD have activated microglia [35], which export copious amounts of glutamate [42]. Glutamate is a mitochondrial toxin [43-45], and is selectively toxic to neurons [46-48]. Could glutamate be the cause of the mitochondrial dysfunction and selective Purkinje neuron degeneration observed in autism? 


\section{Extracellular glutamate transport and receptor activation}

There are two sources of extracellular glutamate near Purkinje neurons. The first is glutamate arising from pre-synaptic depolarization of climbing fiber neurons. This mechanism is estimated to result in synaptic glutamate concentrations in the low $\mathrm{mM}$ range, sufficient to activate all known glutamate receptors [49]. The second source of glutamate can arise from synaptic spillover, which is estimated to be in the $100-200 \mu \mathrm{M}$ range [49], or microglial activation which can result in $\mathrm{mM}$ levels of glutamate [50,51]. In situ, glutamate released during neurotransmission is primarily transported into astrocytes [52]. Accordingly, astrocytes are neuroprotective [53,54] against neuronal glutamate toxicity. Although the average intracellular concentration of glutamate in the central nervous system (CNS) is greater than $10 \mathrm{mM}$ [55], extracellular concentrations in the low $\mu \mathrm{M}$ range are toxic [56]. Therefore all major CNS cell types contain high affinity glutamate transport mechanisms [57] which maintain extracellular concentrations at less than $1 \mu \mathrm{M}$ [55].

There is considerable regional and cell type variability of glutamate transporters. Cerebellar astrocytes have similar $K_{m}$ values for glutamate uptake relative to other brain regions $(\sim 50$ $\mu \mathrm{M})$, however the Vmax of these astrocytes is the lowest of all brain regions studied (2.2 $\mathrm{nmol} / \mathrm{min} / \mathrm{mg}$ protein vs. $>10 \mathrm{nmol} / \mathrm{min} / \mathrm{mg}$ in cortical regions) [58]. The key glutamate transporters in this region and their relative contributions to glutamate uptake have been recently studied extensively [59-63]. The general consensus is that although Bergmann glia express both EAAT2 (GLT-1) and EAAT1 (GLAST), EAAT1 is responsible for the majority of glutamate uptake [63]. Likewise, although Purkinje neurons express both EAAT4 and EAAT3 (EAAC), EAAT4 is the principal glutamate uptake transporter [64]. It has been estimated that $<10 \%$ of glutamate arising from climbing fiber depolarization is taken up by Purkinje neurons [64]. However, it has also been proposed that the neuronal EAAT4 transporter is responsible for maintaining low extracellular glutamate levels in between neuronal firing events [59] and that this transporter has a 20-fold greater affinity for glutamate $(2.5 \mu \mathrm{M})$ [65] vs. EAAT1 $(48 \mu \mathrm{M})$, EAAT2 $(97 \mu \mathrm{M})$, or EAAT3 $(62 \mu \mathrm{M})$ [66]. Although EAAT4 is also present in astrocytes [67], cerebellar Purkinje neurons express the highest levels of EAAT4 in the human brain [68]. These results suggest that there is an inherent weakness in astrocytic glutamate uptake in cerebellar regions These data collectively suggest that chronic low-level exposure to extracellular glutamate would be expected to have a disproportionate effect on these neurons.

Time course studies of glutamate toxicity on neurons [69] and astrocytes [70] suggest that toxicity resulting from chronic exposure to glutamate is mediated by intracellular metabolic disturbances, most notably an increase in oxidative stress and depleted glutathione levels. However, both receptor-dependent and receptor-independent mechanisms of glutamate toxicity have been reported. The N-methyl-D-Aspartate (NMDA) and the a-amino-3hydroxy-5-methyl-4-isoxazole-proprionic acid (AMPA) receptors are the most commonly associated with glutamate toxicity. Glutamate activates NMDA receptors with a EC50 of 2.3 $\mu \mathrm{M}$ and AMPA receptors with a EC50 of $480 \mu \mathrm{M}$ [71]. In neuron-astrocyte co-cultures, the blockade of neuronal NMDA receptors reduces glutamate toxicity whereas the blockade of glutamate transport into astrocytes increases neuronal glutamate toxicity [56]. These results suggest that the acute toxic effect of extracellular glutamate on neurons is primarily mediated via glutamate receptors and that glutamate uptake, primarily into astrocytes, is the principal deactivation / neuroprotection mechanism [72]. Studies involving co-cultures of astrocytes and neurons reveal that astrocytes are neuroprotective and that the uptake and 
metabolic deactivation of glutamate is a key factor in their neuroprotection $[48,53,54]$. Receptor independent mechanisms (i.e. intracellular transport) of extracellular glutamate toxicity are also well documented $[69,70,73]$. The chronic toxic effects of glutamate are most likely mediated via these mechanisms. In particular, Purkinje neuron viability is dependent upon functional glutamate uptake and metabolism in Bergmann glia [60,61]. The regulation of extracellular glutamate levels and their toxicity to Purkinje neurons are determined by the collective ability of these cells reduce extracellular glutamate levels via transport and then to detoxify glutamate via intracellular metabolic deactivation.

\section{Glutamate transport and intracellular metabolism in Purkinje neurons and Bergmann glia}

Each molecule of glutamate transported into the cell is co-transported with 3 sodium $\left(\mathrm{Na}^{+}\right)$ ions, one hydroxyl $\left(\mathrm{OH}^{-}\right)$or chloride $\left(\mathrm{Cl}^{-}\right)$ion, and one proton $\left(\mathrm{H}^{+}\right)$with one potassium $\left(\mathrm{K}^{+}\right)$ ion being transported out, resulting in a net import of one positive charge (glutamate having a negative charge) and thus depolarization of the cell. Both Purkinje neurons and Bergmann glia express $\mathrm{Na}^{+} / \mathrm{K}^{+}$-ATPase [74], which restores the sodium gradient by exporting three $\mathrm{Na}^{+}$ions and importing two $\mathrm{K}^{+}$ions. Therefore, glutamate transport consumes one ATP per glutamate transported. In regards to restoring cytosolic ATP levels both astrocytes and neurons rely upon glucose as the first response [the rate of glycolysis is regulated by cytosolic ATP, see [75] for an excellent review on this topic]. Glucose utilization appears to be roughly equal in both Purkinje neurons and cerebellar astrocytes [76,77]. Predictably, glutamate uptake is therefore a secondary activator of glycolysis [78] and results in the stoichiometric utilization of glucose [79].

Pyruvate is the metabolic product of glycolysis. Studies using $(2-14 \mathrm{C})$-pyruvate (TCA and non-TCA metabolism) indicate that both neurons and astrocytes primarily process pyruvate via the TCA cycle and that glutamate $(50 \%)$ and aspartate $(20 \%)$ are the two key metabolites formed. However, astrocytes also generate significant amounts of alanine with less than $10 \%$ of the label unaccounted for whereas in neurons a small amount of GABA is formed and $20 \%$ of the label is unaccounted for [80]. Studies using $(1-14 \mathrm{C})$-pyruvate (non-TCA metabolism only) indicate that in Purkinje neurons, most of the label ends up in Asp, whereas in cerebellar astrocytes most of the label ends up in alanine [80]. Since the synthesis of aspartate from pyruvate proceeds via oxaloacetate (OAA), mitochondrial pyruvate carboxylation must be active in neurons, as previously reported [81,82]. In contrast, nonTCA cycle processing of pyruvate in astrocytes occurs primarily via alanine aminotransferase. These data clearly indicate that under normal conditions, extra pyruvate is preferentially processed via the first half of the TCA cycle and that glutamate is the predominant non- $\mathrm{CO}_{2}$ product in both neurons and astrocytes. The above data indicate that lactate is definitely not a significant product of pyruvate metabolism in astrocytes, but the possibility exists that up to $20 \%$ of pyruvate could be converted to lactate via lactate dehydrogenase (LDH) in Purkinje neurons. It is interesting to note that Purkinje neurons have a disproportionately high LDH activity relative to other CNS neurons [83].

Studies involving purified mitochondria and cell cultures have repeatedly shown that, in the brain, glutamate is stoichiometrically converted to aspartate [84,85]. However more recent cell culture studies utilizing ${ }^{15} \mathrm{~N}$-glutamate indicate that in astrocytes, glutamate nitrogen is almost exclusively converted to glutamine along with a small but significant formation of alanine $[86,87]$ whereas in neurons, the glutamate nitrogen is almost exclusively converted 
into aspartate [88,89]. In addition, in vitro tracer studies of (U-14C)-L-glutamate reveal that both aspartate and glutamine are labeled with the synaptosomal ratio being 2:1 in favor of aspartate but the astrocytic fraction being just over 1:1 in favor of glutamine [80]. Enzyme activity studies indicate that Purkinje neurons predominantly express aspartate aminotransferase (AAT), a little glutamine synthetase (GS) and almost no glutamate dehydrogenase (GDH), whereas astrocytes and Bergmann glia strongly express GDH and GS with only a minor amount of AAT [90-94]. Clearly, astrocytes and neurons metabolize glutamate differently. However the underlying reason has been difficult to understand until recently. AAT, the favored glutamate-metabolizing enzyme, is ubiquitously distributed in the brain and exists in both the cytosol and mitochondria [89]. The metabolic flux through AAT, especially in the mitochondria, has long been shown to be heavily controlled by the electrogenic mitochondrial aspartate/glutamate carrier (AGC) [95,96], as well as by metabolite substrate availability where the addition of pyruvate (which drives OAA through citrate synthase) or a-ketoglutarate (a-KG) reduces glutamate flux, unlike malate (which increases OAA availability) [85,97]. These effects are dramatically reduced in liver mitochondria which have high GDH activity, exemplifying the brain's reliance on AAT $[85,97]$. Recently, three independent groups have confirmed that, in situ, only neurons express AGC [98-100]. The lack of this carrier in astrocytes explains the increased mitochondrial flux of glutamate into glutamine [101] and aspartate into OAA [102], and the lack of deamination of aspartate in neurons [102].

The subsequent metabolism of aspartate in neurons and astrocytes is even more specialized. First of all, the two key glutamate transporters expressed in astrocytes (EAAT1, EAAT2) have a two times higher affinity for L-aspartate vs. L-glutamate [66], yet the intracellular/extracellular ratio for glutamate in astrocytes is significantly higher [86], which is suggestive of a very rapid intracellular aspartate metabolic rate. Comparison of ${ }^{15} \mathrm{~N}$ aspartate with ${ }^{15} \mathrm{~N}$-glutamate metabolism in cultured astrocytes in the presence of adequate glucose reveals that ${ }^{15} \mathrm{~N}$-aspartate flux is almost two times that of $15 \mathrm{~N}$-glutamate [86,101]. In these two studies, it is clear that the majority of aspartate and glutamate metabolism in astrocytes is occurring in the cytosol and that the principal products are arginine and glutamine, respectively. Perhaps more importantly is that it appears that glutamate transfers its nitrogen to glutamine via deamination in the mitochondria, not transamination, and that the resulting a-KG is metabolized via the TCA cycle [103]. These findings are remarkably consistent with [102] where aspartate was found to be deaminated in astrocytes. The most likely explanation for these findings stems from the work of Fahien et al. [104,105] where it was found that GDH-AAT complexes resulted in the oxidative deamination of aspartate. When the membrane potential gets above -20nA in neurons, EAAT4 actually exports aspartate [65], a property not shared by either EAAT1 [106] or EAAT2 [107], the primary astrocyte transporters. These data strongly suggest that neurons primarily convert glutamate to aspartate and export aspartate to the extracellular space where it can be taken up by astrocytes (Figure 1). Astrocytes, on the other hand primarily neutralize glutamate and aspartate by converting glutamate to glutamine and aspartate to arginine with the excess being metabolized via the TCA cycle.

As discussed above, the preferred fate of glutamate in neurons is the transport of glutamate via the AGC into the mitochondria, conversion to aspartate via AAT, and the export of aspartate via AGC to the cytosol and finally out of the cell via EAAT4. Therefore the maintenance of high flux (and thus detoxification) of glutamate in neurons is principally 
dependent upon mitochondrial aspartate efflux via AGC. This efflux is directly regulated by the mitochondrial ETC proton gradient and indirectly regulated by precursor availability for AAT (i.e. OAA). Aspartate efflux requires that the cytosol is acidic relative to mitochondrial matrix. Glutamate is transported into the mitochondria in its protonated state and aspartate is transported out of the mitochondria in its de-protonated state. Therefore the exchange process results in the net import of one proton per glutamate. This leads to acidification of the mitochondria, reduction in the membrane proton gradient, and thus reduction in aspartate efflux. To maintain the proton gradient, it is essential that the ETC is operating efficiently as it is this process that ejects protons from the mitochondria and maintains the proton gradient. Therefore to restore the electrogenic balance during glutamate exposure, neuronal mitochondria need to convert one $\mathrm{NADH}$ to $\mathrm{NAD}^{+}$per molecule of glutamate imported. The standard hypothesis is that the a-KG formed from AAT is exported out in exchange for cytosolic malate. This malate is then converted to OAA via malate dehydrogenase which consumes one $\mathrm{NAD}^{+}$, producing one $\mathrm{NADH}$ which is then processed by complex I of the ETC. The importance of cytosolic malate in maintaining efficient mitochondrial processing of glutamate cannot be overstated (see [85]). The exported a-KG and aspartate are then converted to glutamate and OAA by cytosolic AAT and the resultant OAA converted to malate in the cytosol. However, under a toxic glutamate load, the cytosolic environment would not favor this reaction. Instead, cytosolic AAT will be driven to aspartate, not glutamate, and since neurons have no other major metabolic pathway for aspartate, the export of aspartate via EAAT4 would be its logical fate. Just as the export of aspartate from mitochondria is the rate limiting step of AAT, total cellular export of aspartate would be rate limiting for the metabolic detoxification of glutamate to aspartate in neurons (Figure 1). Increased levels of pyruvate from stimulated glycolysis combined with reduced mitochondrial capacity for acetyl-CoA utilization (due to mitochondrial OAA being

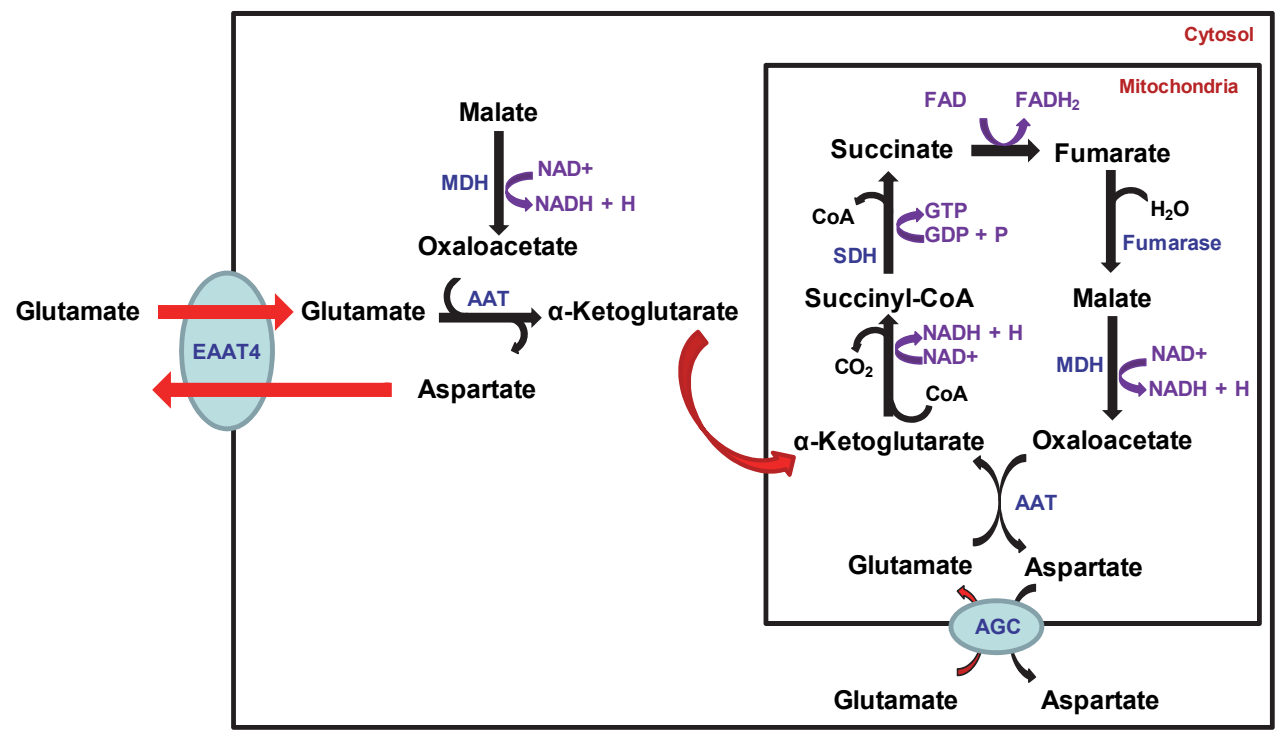

Fig. 1. Neuronal Metabolism of Glutamate 
used to create aspartate instead of citrate) would result in pyruvate being driven to lactate via lactate dehydrogenase ( $\mathrm{LDH})$. The combination of high acidity (from glutamate) and lactate (from glycolysis) would favor the export of lactate via the monocarboxylate transporter 2 (MCT2). Therefore the export of lactate via MCT2 becomes rate limiting for the conversion of pyruvate to lactate via $\mathrm{LDH}$ and the cytosolic regeneration of $\mathrm{NAD}^{+}$(Figure 2). As lactate builds up, the regeneration of $\mathrm{NAD}^{+}$from $\mathrm{LDH}$ will go down. In the mitochondria, as the AGC gets overwhelmed, intra-mitochondrial a-KG goes up and $\mathrm{NADH}$ goes up. This results in a-KG dehydrogenase switching from succinate formation to peroxide formation [108]. The principal mechanism of detoxifying peroxide is via glutathione. The oxidation of GSH is one of the first toxic metabolic consequences of glutamate toxicity in neurons [69], and decreased GSH is a common observation in autism $[2,11-13,109]$.

Unlike neurons, which have metabolic mechanisms that enable it to rapidly cycle glutamate, astrocytes must process the aspartate and glutamate they import. Astrocytes highly express EAAT1 which transports both aspartate and glutamate with high affinity. Astrocytes are far

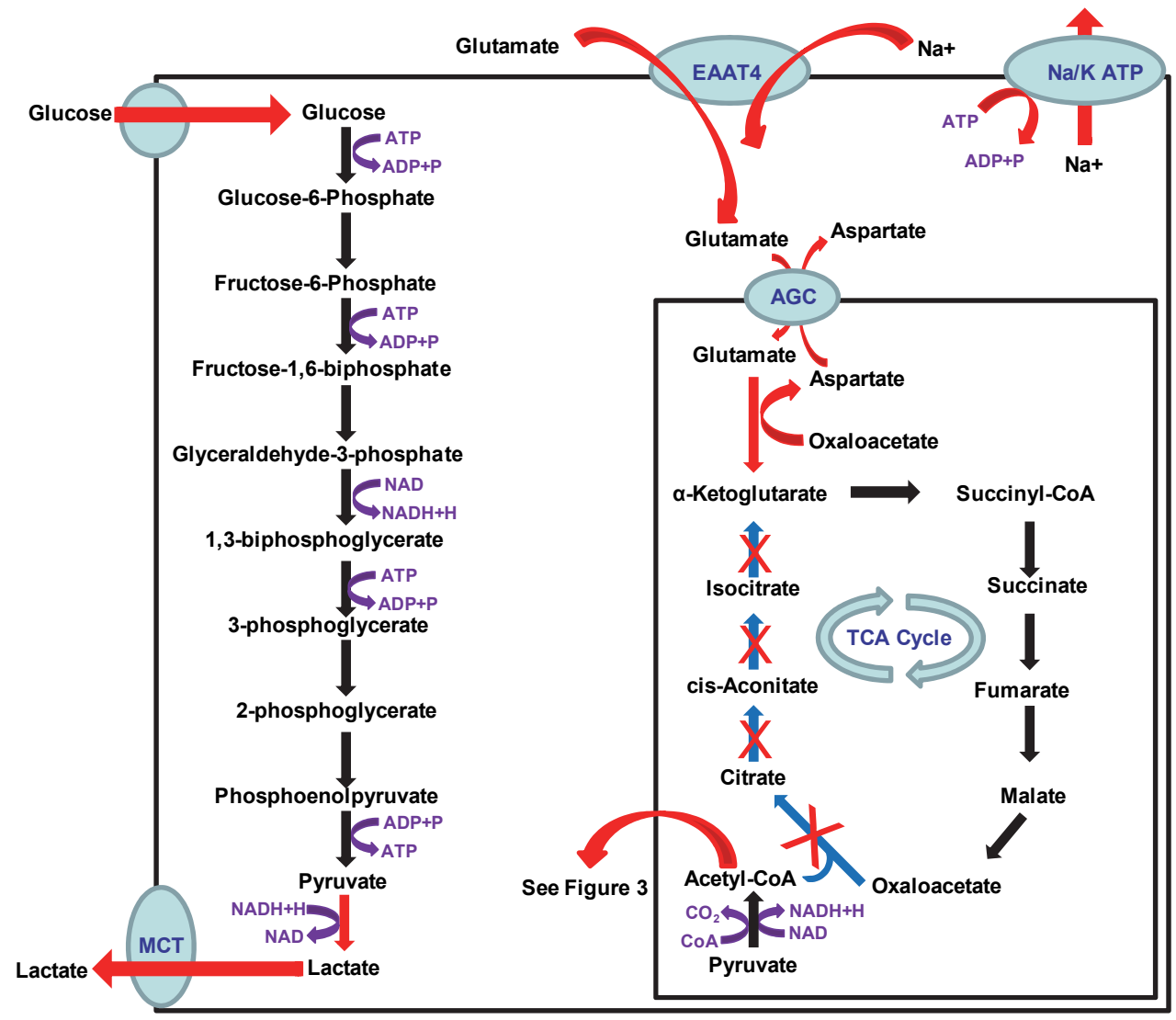

Fig. 2. Effect of Glutamate Transport on Glycolysis and Pyruvate 
more reliant on the mitochondrial TCA cycle than neurons due to the lack of the AGC. Glutamate can enter the mitochondria via the dicarboxylic acid carrier [98]. Once in the mitochondrial matrix, two glutamate molecules can be converted to one a-KG and one glutamine via GDH and GS respectively. a-KG can then directly enter the TCA cycle. Therefore the production of a-KG from glutamate via GDH can completely bypass glucose metabolism. Normally, the primary TCA energy source is acetyl-CoA which can come from either glycolysis (pyruvate) or fatty acid oxidation (palmitate, 16:0) and this acetyl-CoA enters the TCA cycle via citrate synthase, which condenses one OAA with one acetyl-CoA to form citrate, which then goes through the cycle releasing two $\mathrm{CO}_{2}$ molecules ultimately leading back to OAA. Since a-KG can be derived from either citrate or glutamate, the oxidative capacity of the TCA cycle can be broken into two parts: OAA to a-KG via citrate and then aKG to OAA, independent of citrate (or acetyl-CoA for that matter). It turns out that this latter part of the TCA cycle has three times the capacity vs. the former [110]. So, for every one acetylCoA entering via glycolysis or fatty acid oxidation, the TCA cycle can accept two additional aKG molecules. Since the primary metabolic route of glutamate directly creates $\mathrm{a}-\mathrm{KG}$, this provides an effective means of detoxifying glutamate in astrocytes.

The TCA cycle has multiple regulatory systems. One of the more important ones is the succinyl-CoA/acetyl-CoA ratio. As this ratio goes up both citrate synthase and a-KG dehydrogenase are inhibited. However, the inhibition of a-KG dehydrogenase can be overridden by high levels of $\mathrm{a}-\mathrm{KG}$, as is the case when glutamate is present in abundance. So the net effect of glutamate loading is to inhibit citrate synthase, which shuts down both aerobic glycolysis and fatty acid oxidation. However, this intra-mitochondrial glutamate detoxification pathway consumes two $\mathrm{NAD}^{+}$, which need to be restored by the ETC. When the succinyl-CoA:acetyl-CoA ratio gets too high, respiration is shut down. When cytosolic glutamate accumulates, cytosolic conversion to aspartate occurs resulting in a-KG. Unlike the aspartate shuttle which energetically operates in only one direction, the a-KG transporter is completely reversible, which enables cytosolic a-KG to equilibrate with mitochondrial levels; this leads to increased mitochondrial $a-K G$, which will over-ride the aKG dehydrogenase inhibition caused by a high succinyl-CoA:acetyl-CoA ratio. Since these conditions also create conditions of low $\mathrm{NAD}^{+} / \mathrm{NADH}$ ratio, the a-KG dehydrogenase reaction switches from creating succinate to creating hydrogen peroxide [108]. This hydrogen peroxide must be detoxified by GSH, which is why decreased GSH occurs rapidly upon glutamate loading. Furthermore, GSH is exclusively synthesized in the cytosol and then transported to the mitochondria, a process that is inhibited by glutamate [111]. The shut-down of mitochondrial oxidative phosphorylation results in a decrease in the ATP:ADP ratio which further turns on hexokinase, and since pyruvate is blocked from entering the TCA cycle, the anaerobic pathway becomes a critical short-term source of ATP. However, for anaerobic glycolysis not to become self-limiting, the cell needs to export lactate. Astrocytes export lactate via MCT1 [112].

\section{Effect of glutamate on neuronal and astrocytic glutathione metabolism}

Oxidative metabolism generates reactive oxygen species (ROS). The primary intracellular neutralizer of ROS is GSH. The cystine-glutamate antiporter, which is highly active in microglia [42], is also highly expressed on both astrocytes in the granular layer and on Bergmann glia in the molecular layer, but not on oligodendrocytes or Purkinje neurons [113]. This transporter is an energy-neutral ion exchange protein that operates according to 
the relative intracellular and extracellular concentrations of glutamate and cystine [114]. The fact that intracellular glutamate levels are orders of magnitude greater than extracellular glutamate means that this transporter's primary purpose in astrocytes is for the import of cystine and does not contribute significantly under resting conditions to the uptake of glutamate. Astrocytes contain high concentrations of glutathione relative to neurons (more than 20 times higher [115]). In addition, resistance to glutamate toxicity in astrocytes is primarily mediated by glutathione [70]. Glutamate-derived oxidative phosphorylation in astrocytes is about twenty times that in neurons [116] and $>80 \%$ of extracellular glutamate is transported into astrocytes. Since intracellular glutamate stimulates both glutathione synthesis [2,117] and the inward flow of cystine [114], this anti-porter provides astrocytes with a glutamate-dependent means of maintaining high GSH levels. Neurons, on the other hand, utilize EAAT2 and EAAT3 to import cysteine for the synthesis of GSH and this import process is competitively inhibited by glutamate [118]. Therefore the net effect of high levels of extracellular glutamate arising from activated microglia would be to preferentially starve neurons of cysteine in favor of ensuring adequate astrocytic levels of GSH. This observation is consistent with both in vitro studies that show decreased GSH levels in neurons as a result of glutamate treatment $[69,119]$ and clinical studies that show that GSH levels are reduced in autism [2,11-14]. Furthermore, the metabolic precursors of GSH, methionine and cysteine, are also reduced in autism $[2,12,13]$. Collectively, these data suggest that glutamate toxicity resulting from activated microglia would simultaneously increase astrocytic GSH synthesis and oxidation, which would be expected to result in decreased levels of both GSH precursors and GSH, conditions shown to be present in autistic children.

\section{Impaired mitochondrial fatty acid oxidation in autism}

Glutamate-induced mitochondrial dysfunction indirectly and selectively suppresses mitochondrial fatty acid $\beta$-oxidation. The formation of aspartate from glutamate via the transaminase reaction outcompetes citrate synthase for OAA resulting in a dramatic decrease in citrate and effectively shutting down mitochondrial processing of acetyl-CoA [2]. High levels of acetyl-CoA then feedback inhibit mitochondrial $\beta$-oxidation. Indirectly, the energetic outward transport of aspartate leads to an increased flux through malate dehydrogenase, which causes an increase in the mitochondrial NADH/NAD ${ }^{+}$ratio, which inhibits $\beta$-oxidation at the $\mathrm{NAD}^{+}$-linked $\beta$-hydroxyacyl-CoA dehydrogenase reaction [120]. The extra-mitochondrial effects of disrupted mitochondrial fatty acid $\beta$-oxidation are related to the carnitine-dependency of this system. Carnitine performs two essential metabolic functions. Its primary and most widely recognized function is to shuttle fatty acids (palmitate (16:0) and stearate (18:0)) from the cytosol into the mitochondrial matrix where it can be $\beta$-oxidized to acetyl-CoA. Its secondary, less recognized function is to shuttle excess acetyl-CoA out of the mitochondrial matrix to the cytosol (for reviews see [121-124]).

If mitochondrial acetyl-CoA metabolism is impaired, carnitine-fatty acid cycling is impaired and carnitine usage is shifted to acetyl-carnitine from palmitoyl-carnitine (Figure 3). This results in a build-up of palmitate in the cytosol. Normally, peroxisomes only oxidize $20-30 \%$ of cellular palmitate $[125,126]$. Fatty acid transport into peroxisomes occurs via their CoA esters, not carnitine. Peroxisomes are designed to consume excess cytosolic fatty acids. However, unlike mitochondria fatty acid $\beta$-oxidation, which is a catabolic, energy generating process [127], peroxisomal $\beta$-oxidation plays primarily an anabolic role where 
imported fatty acid-CoA is partially $\beta$-oxidized to acetyl-CoA and medium-chain fatty acids [128]. Within the peroxisome, this acetyl-CoA is used for the synthesis of the fatty alcohol that ultimately becomes the sn-1 ether in plasmalogens [129-132]. In addition to the synthesis of the 1-O-alkyl bond of plasmalogens, the synthesis of docosahexaenoic acid (DHA) also involves a peroxisomal component. Following the synthesis of 24:6 (tetracosahexaenoic acid) via fatty acid elongation and desaturation of 18:3 (a-linolenic acid) in the endoplasmic reticulum, 24:6 is transported to the peroxisome where it is $\beta$-oxidized to 22:6 (DHA) [133]. Peroxisomal acetyl-CoA is normally the major source of cytosolic acetylCoA. Within the cytosol, this acetyl-CoA is used for cholesterol synthesis $[126,132]$ and other lipogenic processes such as VLCFA synthesis [134]. Findings of elevated DHA [135], PlsEtn,

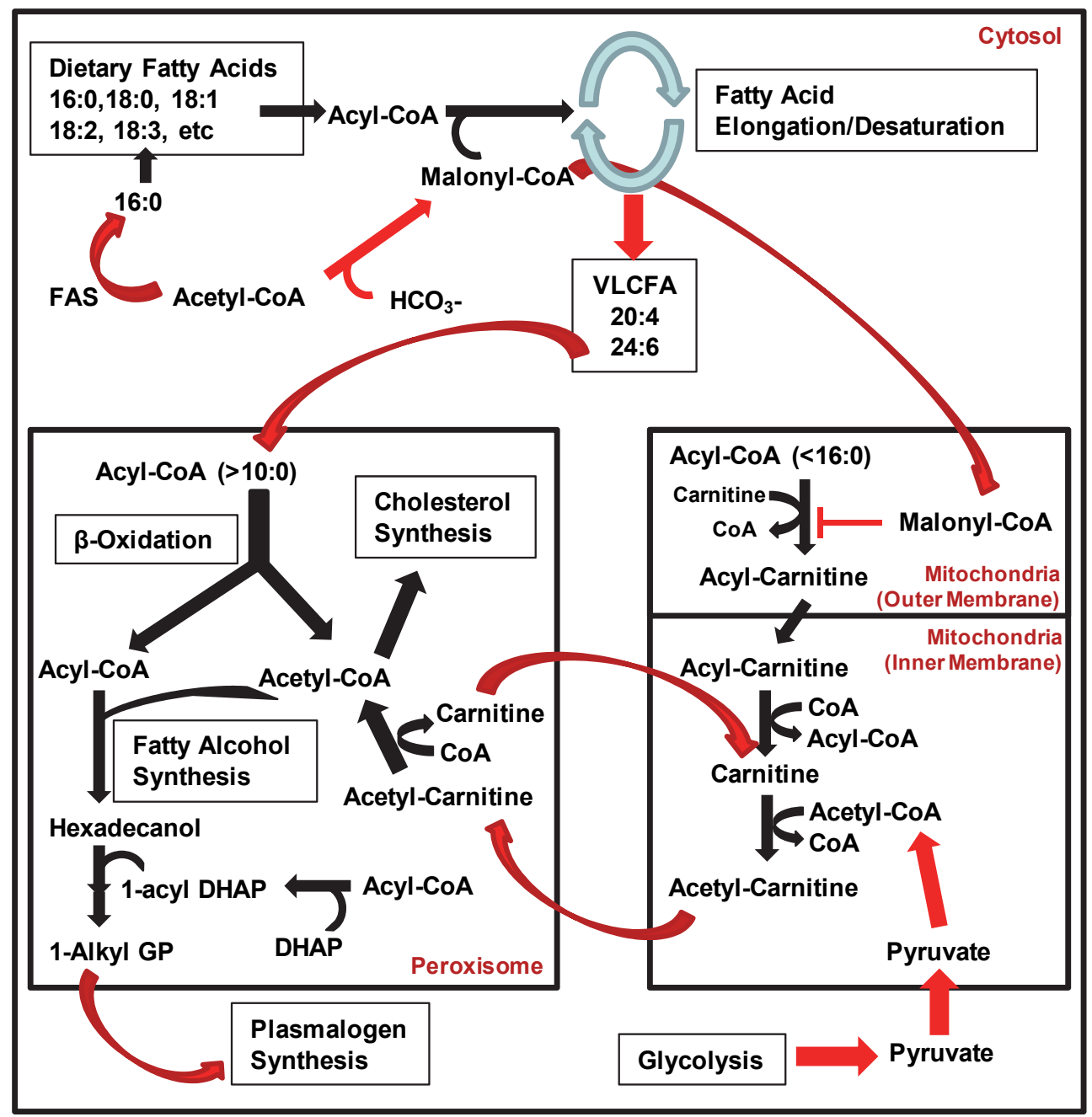

Fig. 3. Metabolic Consequences of Impaired Mitochondrial Tricarboxylic Acid Cycle 
and VLCFA levels [2] in autism plasma are consistent with a combined decrease in mitochondrial $\beta$-oxidation and an increase in peroxisomal $\beta$-oxidation. In vitro cell culture assays performed on hepatocytes, neurons and astrocytes revealed that glutamate exposure decreased 16:0 mitochondrial $\beta$-oxidation and increased peroxisomal processing of 16:0 and cytosolic fatty acid elongation/desaturation [2].

It is highly speculative but nonetheless tempting to associate some of the epigenetic findings in autism to the recently identified role of mitochondrial acetylcarnitine in nuclear histone acetylation [136]. The acetylcarnitine formed in mitochondria from acetyl-CoA is indeed translocated to cytosol as commonly known, but also to the nucleus where it is converted to acetyl-CoA, which is then used as a main source of acetyl groups for histone acetylation [136]. The situation of high cytosolic acetylcarnitine described above would therefore be expected to enhance histone acetylation, since the other putative source of nuclear acetyl groups, the ATPcitrate lyase pathway, would similarly face high citrate. On the other hand, acetylation and methylation are altered in Rett syndrome, an autism spectrum disorder caused by mutations in MeCP2, a global transcriptional repressor of methylated promoters during postnatal brain development [137]. Brains from $\mathrm{MeCP}^{308 / y}$ mutant mice exhibit elevated histone $\mathrm{H} 3$ acetylation [138], similarly to brains from Rett syndrome patients with mutant MeCP2 or autistic brains with MeCP2 deficiency [139], which can be explained by the role of MeCP2 in HDAC's recruitment [139]. Higher histone acetylation in Rett syndrome and autism with MeCP2 deficiency may therefore be correlated to the putative higher histone acetylation resulting from the mitochondrial dysfunction model described above.

\section{Mitochondrial dysfunction and microglial activation}

As exhaustively reviewed by Chauhan and Chauhan [10], the brain is highly vulnerable to oxidative stress, particularly during the early part of development. The reactive oxygen species (ROS) generated by oxidative stress is a cause of lipid peroxidation, which has been reported to be increased in serum and urine from autistic children [14,15]. Lipid peroxidation is a well established cause of reactive aldehyde generation, which plays a key role in apoptotic mechanisms leading to both neuronal and glial cell death [140]. Damaged cells further stimulate microglial activation, which also contributes to free radical production [141].

VLCFA accumulation is also a cause of microgliosis, as evidenced by microglial inflammation in subcortical region in X-adrenoleukodystrophy [142]. The increase in plasmalogens is expected to aggravate the damage caused by VLCFA accumulation since, as recently reported, VLCFA-induced microgliosis seems to be dependent on plasmalogens [143]. The decrease in GSH and the increase in VLCFA and/or plasmalogens observed in autistic subjects are therefore expected to contribute to continuous microglial activation in a positive feedback [2].

The decrease in GSH and the increase in VLCFA and/or plasmalogens observed in autistic subjects [2] are therefore expected to both contribute to continuous microglial activation in a positive feedback or "vicious cycle" [144]. Microglial activation and subsequent "immunoexcitotoxicity" by glutamate are growingly proposed as a central causative model in autism [145].

\section{Mitochondrial dysfunction and the observed gender bias in autism}

There is no escaping the irrefutable epidemiological fact that autism exhibits a marked gender bias with approximately four times more males diagnosed as females [146-148]. 
Prepubertal boys and girls are different, not just genetically, but biochemically as well. Prepubertal boys and girls have similar testosterone levels (3.9 vs. $4.7 \mathrm{ng} / \mathrm{dL}$ in [149] and 0.41 vs. $0.45 \mathrm{nM}$ in [150] for 17 B-testosterone), but prepubertal girls have 4 -fold higher levels of estrogen than prepubertal boys on average $(5.9+/-9.7$ pmol /L vs. $1.5+/-4.1)$ [151] or at least 3 times higher $(9.6$ pmol/L vs. <3.7 ) [150] for B-estradiol; this difference masks a very high heterogeneity in the level distribution, with undetectable levels for some girls and elevated levels for some boys [150,151,161]. Estrogen is a well known neuroprotectant, especially in glutamate induced neurotoxicity [152-160]. Interestingly, the serum distribution levels in the Courant et al. study [150] reveal that if $5 \mathrm{pmol} / \mathrm{L}$ were arbitrarily selected as the minimal protective cut-off value, less than $1 / 3$ of girls would be at risk versus $3 / 4$ of boys, a gender bias identical to that observed in autism.

Multiple mechanisms for B-estradiol neuroprotection have been demonstrated and most involve the mitochondria $[162,163]$. The chemical structure of estrogens, with the presence of a phenolic A-ring, directly participates in neuroprotection as the "chemical shield" scavenges reactive oxygen species [164]. Another interesting mechanism seems to be structural as estradiol intercalates within cell membranes, preserving mitochondrial integrity [162].

But the most powerful support for estrogen protection as the cause of the gender bias in autism comes from the work of Djouadi and colleagues [165]. The authors studied the simultaneous inhibition of mitochondrial 16:0 processing via an irreversible pharmacological CPT-I inhibitor (Etomoxir) and peroxisome proliferation via PPARa double knockout (-/-). They observed an unexpected gender effect. $100 \%$ of the male mice died but only $25 \%$ of the female mice died. $100 \%$ protection of the male mice was afforded by pretreatment of the mice with $\beta$-estradiol. Clearly, $\beta$-estradiol is protective against complications arising from impaired extra mitochondrial processing of 16:0. In addition, it was observed that blood glucose levels of female PPARa (-/-) mice recovered relatively quickly to Etomoxir-induced hypoglycemia but that male PPARa (-/-) did not. $\beta$-Estradiol pretreated male PPARa (-/-) exhibited a similar result as female PPARa (-/-) mice. These data are consistent with the data of [166] in that recovery from insulin-induced hypoglycemia was significantly slower in autistic children versus non-autistic children. This hypoglycemic response is relevant in that glutamate toxicity creates localized hypoglycemia presumably due to increased glucose uptake [156]. In addition, $\beta$-estradiol increases lactate dehydrogenase activity and synthesis [167] as well as lactate export [156], which increases glycolysis flux capacity. $\beta$-estradiol also increases cytosolic acetyl-CoA utilization by increasing fatty acid synthase and acetyl-CoA carboxylase activity [168], which would irreversibly remove acetyl-CoA from the cytosolic pool and free up cytosolic carnitine, which would enhance mitochondrial processing of 16:0.

\section{Mitochondrial dysfunction and abnormal brain growth in autism}

Abnormal brain growth, particularly in cerebellar white matter [169-171], has been observed in autism. No direct link between mitochondrial dysfunction and abnormal brain growth has been proposed. However, the pro-osmotic effect of glutamate import in astrocytes [2], has been proposed as a putative mechanism. As mentioned earlier, the import of a glutamate molecule results in a net import of one positive charge, which in astrocytes results in significant swelling (up to $9 \%$ increase in volume) [172]; the swelling ceases as extracellular glutamate levels decrease [172]. It is therefore possible that the increased 
circumference observed in autism is the result of continuously high extracellular concentrations of glutamate.

\section{Mitochondrial dysfunction and seizures in autism}

Epilepsy is a common clinical feature associated to autism; it is conservatively estimated that $20-25 \%$ children with ASD present with seizures, the most frequent type being complex partial seizures [173]. Oxidative stress [174] and subsequent mitochondrial dysfunction [175] are growingly recognized as being linked to seizure susceptibility, and very interestingly, may actually be contributing factors to epileptic susceptibility, at least in the case of acquired epilepsy, as after brain injury [175]. In their excellent review of the association between mitochondrial dysfunction and temporal lobe epilepsy, Waldbaum and Patel remind that the first suggestion of mitochondrial dysfunction in epilepsy arose from the observation that epilepsy is frequent in inherited mitochondrial disorders such as those associated with childhood encephalopathies [175]. Suggested causative mechanisms underlying a mitochondrial role in epilepsy are imbalances in glutamate and/or calcium signalling [176,177], or respiratory chain complex I dysfunction [178].

\section{Mitochondrial dysfunction and visual acuity}

There is still a debate as to whether children with ASD display a higher visual acuity than normally developing children, but numerous reports, even anecdotic, seem to support this common observation from parents $[179,180]$. The importance of dietary long chain polyunsaturated fatty acids, and of DHA particularly, for visual development has been demonstrated by several clinical trials in infants, showing benefits for DHA-rich formulas fed on longer periods [181]. It is therefore tempting to associate the "eagle-eyed" visual acuity detected in children with ASD [179] to the higher content of docosahexaenoic acid detected in plasma $[2,135]$ and presumably present in retina. This assumption must however be nuanced by the fact that benefits on visual acuity were reported for DHA fed and monitored through the diet, with few studies monitoring the omega-3 body burden [181,182]; the umbilical cord DHA content has however been found to be positively correlated with visual system function [182]. Another nuance is the limit of the benefits to visual acuity contributed by DHA: in the DIAMOND study, which monitored the dose effect of DHA supplementation in infant formulas, DHA supplementation improved visual acuity but this improvement did not show a dose response as visual acuity did not improve further with higher DHA content, even if this higher dietary DHA concentration was reflected in higher DHA concentration in red blood cells [181]. Overall, it seems that DHA concentration is positively correlated with future visual function during gestation and infancy, with the effect of dose and endogenous/dietary balance requiring further investigation.

\section{Conclusive remarks}

In summary, there is a significant amount of direct and indirect evidence of mitochondrial dysfunction in autism. The metabolic cascade observed in autism due to mitochondrial dysfunction can be reproduced with glutamate. Glutamate is the most obvious perpetrator due to its role in microgliosis and the selective glutamergic architecture of Purkinje neurons 
and Bergmann glia. The data and research performed to date regarding autism and mitochondrial dysfunction however, are unable to ascertain whether subjects who suffer from autism have a yet undetermined mitochondrial weakness that leads to mitochondrial dysfunction under circumstances that would be tolerated by non-autistic subjects, or whether subjects with autism have some other abnormality that results in chronic microglial activation and subsequent "immunoexcitotoxicity" by glutamate [145], but with otherwise normal mitochondrial function. Regardless of the cause of the mitochondrial dysfunction and related consequences, the female gender protection from autism appears to be due to circulating $\beta$-estradiol levels and its buffering effects on glucose metabolism. Accordingly, dietary and pharmacological therapies directed at the treatment of autism should thus focus on reducing intracellular mitochondrial demand by either reducing cellular uptake (or extracellular production) of mitochondrial demanding substrates (i.e. glutamate or glucose) or increasing cellular export of mitochondrial or glycolysis products (i.e. aspartate, pyruvate or lactate).

\section{References}

[1] Haas RH. Autism and mitochondrial disease. Dev Disabil Res Rev 2010;16 (2):144-53.

[2] Pastural E, Ritchie S, Lu Y, Jin W, Kavianpour A, Su-Myat KK, Heath D, Wood PL, Fisk M, Goodenowe DB. Novel Plasma Phospholipid Biomarkers of Autism: Mitochondrial Dysfunction as a Putative Causative Mechanism. Prostaglandins Leukot Essent Fatty Acids 2009;81 (4):253-64.

[3] Rossignol DA, Frye RE. Mitochondrial dysfunction in autism spectrum disorders: a systematic review and meta-analysis. Mol Psychiatry 2011.

[4] Oliveira G, Diogo L, Grazina M, Garcia P, Ataide A, Marques C, Miguel T, Borges L, Vicente AM, Oliveira CR. Mitochondrial dysfunction in autism spectrum disorders: a population-based study. Dev Med Child Neurol 2005;47 (3):185-9.

[5] Laszlo A, Horvath E, Eck E, Fekete M. Serum serotonin, lactate and pyruvate levels in infantile autistic children. Clin Chim Acta 1994;229 (1-2):205-7.

[6] Filipek PA, Juranek J, Nguyen MT, Cummings C, Gargus JJ. Relative carnitine deficiency in autism. J Autism Dev Disord 2004;34 (6):615-23.

[7] Giulivi C, Zhang YF, Omanska-Klusek A, Ross-Inta C, Wong S, Hertz-Picciotto I, Tassone F, Pessah IN. Mitochondrial dysfunction in autism. JAMA 2010;304 (21):2389-96.

[8] Pons R, Andreu AL, Checcarelli N, Vila MR, Engelstad K, Sue CM, Shungu D, Haggerty $\mathrm{R}$, de Vivo DC, DiMauro S. Mitochondrial DNA abnormalities and autistic spectrum disorders. J Pediatr 2004;144 (1):81-5.

[9] Weissman JR, Kelley RI, Bauman ML, Cohen BH, Murray KF, Mitchell RL, Kern RL, Natowicz MR. Mitochondrial disease in autism spectrum disorder patients: a cohort analysis. PLoS ONE 2008;3 (11):e3815.

[10] Chauhan A, Chauhan V. Oxidative stress in autism. Pathophysiology 2006;13 (3):171-81.

[11] Geier DA, Kern JK, Garver CR, Adams JB, Audhya T, Geier MR. A Prospective Study of Transsulfuration Biomarkers in Autistic Disorders. Neurochem Res 2008.

[12] James SJ, Cutler P, Melnyk S, Jernigan S, Janak L, Gaylor DW, Neubrander JA. Metabolic biomarkers of increased oxidative stress and impaired methylation capacity in children with autism. Am J Clin Nutr 2004;80 (6):1611-7.

[13] Kern JK, Jones AM. Evidence of toxicity, oxidative stress, and neuronal insult in autism. J Toxicol Environ Health B Crit Rev 2006;9 (6):485-99. 
[14] Chauhan A, Chauhan V, Brown WT, Cohen I. Oxidative stress in autism: increased lipid peroxidation and reduced serum levels of ceruloplasmin and transferrin--the antioxidant proteins. Life Sci 2004;75 (21):2539-49.

[15] Ming X, Stein TP, Brimacombe M, Johnson WG, Lambert GH, Wagner GC. Increased excretion of a lipid peroxidation biomarker in autism. Prostaglandins Leukot Essent Fatty Acids 2005;379 (5):379-84.

[16] Bernier FP, Boneh A, Dennett X, Chow CW, Cleary MA, Thorburn DR. Diagnostic criteria for respiratory chain disorders in adults and children. Neurology 2002;59 (9):1406-11.

[17] Shoffner J, Hyams L, Langley GN, Cossette S, Mylacraine L, Dale J, Ollis L, Kuoch S, Bennett K, Aliberti A, Hyland K. Fever plus mitochondrial disease could be risk factors for autistic regression. J Child Neurol;25 (4):429-34.

[18] Abrahams BS, Geschwind DH. Advances in autism genetics: on the threshold of a new neurobiology. Nat Rev Genet 2008;9 (5):341-55.

[19] Oliveira GD, L; Grazina, M; Garcia, P; Ataíde, A; Marques, C; Miguel, T; Borges, L; Vicente, AM; Oliveira, CR. Mitochondrial dysfunction in autism spectrum disorders: a population-based study. Dev Med Child Neurol 2005;47 (3):185-9.

[20] Autism Genome Project Consortium SP, Paterson AD, Zwaigenbaum L, Roberts W, Brian J, Liu XQ, Vincent JB, Skaug JL, Thompson AP, Senman L, Feuk L, Qian C, Bryson SE, Jones MB, Marshall CR, Scherer SW, Vieland VJ, Bartlett C, Mangin LV, Goedken R, Segre A, Pericak-Vance MA, Cuccaro ML, Gilbert JR, Wright HH, Abramson RK, Betancur C, Bourgeron T, Gillberg C, Leboyer M, Buxbaum JD, Davis KL, Hollander E, Silverman JM, Hallmayer J, Lotspeich L, Sutcliffe JS, Haines JL, Folstein SE, Piven J, Wassink TH, Sheffield V, Geschwind DH, Bucan M, Brown WT, Cantor RM, Constantino JN, Gilliam TC, Herbert M, Lajonchere C, Ledbetter DH, Lese-Martin C, Miller J, Nelson S, Samango-Sprouse CA, Spence S, State M, Tanzi RE, Coon H, Dawson G, Devlin B, Estes A, Flodman P, Klei L, McMahon WM, Minshew N, Munson J, Korvatska E, Rodier PM, Schellenberg GD, Smith M, Spence MA, Stodgell C, Tepper PG, Wijsman EM, Yu CE, Rogé B, Mantoulan C, Wittemeyer K, Poustka A, Felder B, Klauck SM, Schuster C, Poustka F, Bölte S, Feineis-Matthews S, Herbrecht E, Schmötzer G, Tsiantis J, Papanikolaou K, Maestrini E, Bacchelli E, Blasi F, Carone S, Toma C, Van Engeland H, de Jonge M, Kemner C, Koop F, Langemeijer M, Hijmans C, Staal WG, Baird G, Bolton PF, Rutter ML, Weisblatt E, Green J, Aldred C, Wilkinson JA, Pickles A, Le Couteur A, Berney T, McConachie H, Bailey AJ, Francis K, Honeyman G, Hutchinson A, Parr JR, Wallace S, Monaco AP, Barnby G, Kobayashi K, Lamb JA, Sousa I, Sykes N, Cook EH, Guter SJ, Leventhal BL, Salt J, Lord C, Corsello C, Hus V, Weeks DE, Volkmar F, Tauber M, Fombonne E, Shih A, Meyer KJ. Mapping autism risk loci using genetic linkage and chromosomal rearrangements. Nature Genetics 2007;39 (3):319-28.

[21] Ramoz N, Reichert J, Smith CJ, Silverman JM, Bespalova IN, Davis KL, Buxbaum JD. Linkage and association of the mitochondrial aspartate/glutamate carrier SLC25A12 gene with autism. AM J Psychiatry 2004;161 (4):662-9.

[22] Segurado R, Conroy J, Meally E, Fitzgerald M, Gill M, Gallagher L. Confirmation of association between autism and the mitochondrial aspartae/glutamate carrier 
SLC25A2 gene on chromosome 2q31. American Journal of Psychiatry 2005;162:2182-4.

[23] Lepagnol-Bestel AM, Maussion G, Boda B, Cardona A, Iwayama Y, Delezoide A, Moalic J, Muller D, Dean B, Yoshikawa T, Gorwood P, Buxbaum J, Ramoz N, Simmoneau M. SLC25A12 expression is associated with neurite outgrowth and is upregulated in the prefontal cortex of autistic subjects. Molecular Psychiatry 2008.

[24] Lasorsa FM, Pinton P, Palmieri L, Fiermonte G, Rizzuto R, F. P. Recombinant expression of the $\mathrm{Ca}(2+)$-sensitive aspartate/glutamate carrier increases mitochondrial ATP production in agonist-stimulated Chinese hamster ovary cells. J Biol Chem 2003;278 (40):38686-92.

[25] Filipek PA, Juranek J, Smith M, Mays LZ, Ramos ER, Bocian M, Masser-Frye D, Laulhere TM, Modahl C, Spence MA, Gargus JJ. Mitochondrial dysfunction in autistic patients with 15q inverted duplication. Ann Neurol 2003;53 (6):801-4.

[26] Connolly BS, Feigenbaum AS, Robinson BH, Dipchand AI, Simon DK, Tarnopolsky MA. MELAS syndrome, cardiomyopathy, rhabdomyolysis, and autism associated with the A3260G mitochondrial DNA mutation. Biochem Biophys Res Commun 2010.

[27] Elliott HR, Samuels DC, Eden JA, Relton CL, Chinnery PF. Pathogenic mitochondrial DNA mutations are common in the general population. Am J Hum Genet 2008;83 (2):254-60.

[28] Herbert MR. Contributions of the environment and environmentally vulnerable physiology to autism spectrum disorders. Curr Opin Neurol;23 (2):103-10.

[29] MacFabe DF, Cain DP, Rodriguez-Capote K, Franklin AE, Hoffman JE, Boon F, Taylor AR, Kavaliers M, Ossenkopp KP. Neurobiological effects of intraventricular propionic acid in rats: possible role of short chain fatty acids on the pathogenesis and characteristics of autism spectrum disorders. Behav Brain Res 2007;176 (1):14969.

[30] Thomas RH, Foley KA, Mepham JR, Tichenoff LJ, Possmayer F, MacFabe DF. Altered brain phospholipid and acylcarnitine profiles in propionic acid infused rodents: further development of a potential model of autism spectrum disorders. J Neurochem 2010;113 (2):515-29.

[31] Rasalam AD, Hailey H, Williams JH, Moore SJ, Turnpenny PD, Lloyd DJ, Dean JC. Characteristics of fetal anticonvulsant syndrome associated autistic disorder. Dev Med Child Neurol 2005;47 (8):551-5.

[32] Farkas V, Bock I, Cseko J, Sandor A. Inhibition of carnitine biosynthesis by valproic acid in rats--the biochemical mechanism of inhibition. Biochem Pharmacol 1996;52 (9):1429-33.

[33] Sanders AP, Schaefer DJ, Joines WT. Microwave effects on energy metabolism of rat brain. Bioelectromagnetics 1980;1 (2):171-81.

[34] Block ML, Calderon-Garciduenas L. Air pollution: mechanisms of neuroinflammation and CNS disease. Trends Neurosci 2009;32 (9):506-16.

[35] Vargas DL, Nascimbene C, Krishnan C, Zimmerman AW, Pardo CA. Neuroglial activation and neuroinflammation in the brain of patients with autism. Ann Neurol 2005;57 (1):67-81. 
[36] Chen L, Yokel RA, Hennig B, Toborek M. Manufactured aluminum oxide nanoparticles decrease expression of tight junction proteins in brain vasculature. J Neuroimmune Pharmacol 2008;3 (4):286-95.

[37] Klintworth H, Garden G, Xia Z. Rotenone and paraquat do not directly activate microglia or induce inflammatory cytokine release. Neurosci Lett 2009;462 (1):1-5.

[38] Schmidt CW. Mito-Conundrum: Unraveling Environmental Effects on Mitochondria. Environ Health Perspect 2010;118:a292-a7.

[39] Palmieri L, Persico AM. Mitochondrial dysfunction in autism spectrum disorders: cause or effect? Biochim Biophys Acta;1797 (6-7):1130-7.

[40] Palmen SJ, van Engeland H, Hof PR, Schmitz C. Neuropathological findings in autism. Brain 2004;127 (Pt 12):2572-83.

[41] Courchesne E. Brainstem, cerebellar and limbic neuroanatomical abnormalities in autism. Curr Opin Neurobiol 1997;7 (2):269-78.

[42] Domercq M, Sanchez-Gomez MV, Sherwin C, Etxebarria E, Fern R, Matute C. System xc- and glutamate transporter inhibition mediates microglial toxicity to oligodendrocytes. J Immunol 2007;178 (10):6549-56.

[43] Khodorov BI. Mechanisms of destabilization of Ca2+-homeostasis of brain neurons caused by toxic glutamate challenge. Membr Cell Biol 2000;14 (2):149-62.

[44] Pereira CF, Oliveira CR. Oxidative glutamate toxicity involves mitochondrial dysfunction and perturbation of intracellular Ca2+ homeostasis. Neurosci Res 2000;37 (3):227-36.

[45] Stout AK, Raphael HM, Kanterewicz BI, Klann E, Reynolds IJ. Glutamate-induced neuron death requires mitochondrial calcium uptake. Nat Neurosci 1998;1 (5):36673.

[46] Liang J, Takeuchi H, Doi Y, Kawanokuchi J, Sonobe Y, Jin S, Yawata I, Li H, Yasuoka S, Mizuno T, Suzumura A. Excitatory amino acid transporter expression by astrocytes is neuroprotective against microglial excitotoxicity. Brain Res 2008;1210:11-9.

[47] Piani D, Fontana A. Involvement of the cystine transport system xc- in the macrophageinduced glutamate-dependent cytotoxicity to neurons. J Immunol 1994;152 (7):3578-85.

[48] Zhao W, Xie W, Le W, Beers DR, He Y, Henkel JS, Simpson EP, Yen AA, Xiao Q, Appel $\mathrm{SH}$. Activated microglia initiate motor neuron injury by a nitric oxide and glutamate-mediated mechanism. J Neuropathol Exp Neurol 2004;63 (9):964-77.

[49] Dzubay JA, Jahr CE. The concentration of synaptically released glutamate outside of the climbing fiber-Purkinje cell synaptic cleft. J Neurosci 1999;19 (13):5265-74.

[50] McNaught KS, Jenner P. Extracellular accumulation of nitric oxide, hydrogen peroxide, and glutamate in astrocytic cultures following glutathione depletion, complex I inhibition, and/or lipopolysaccharide-induced activation. Biochem Pharmacol 2000;60 (7):979-88.

[51] Yawata I, Takeuchi H, Doi Y, Liang J, Mizuno T, Suzumura A. Macrophage-induced neurotoxicity is mediated by glutamate and attenuated by glutaminase inhibitors and gap junction inhibitors. Life Sci 2008;82 (21-22):1111-6.

[52] McLennan H. The autoradiographic localization of L-[3h]glutamate in rat brain tissue. Brain Res 1976;115 (1):139-44.

[53] Brown DR. Neurons depend on astrocytes in a coculture system for protection from glutamate toxicity. Mol Cell Neurosci 1999;13 (5):379-89. 
[54] Rosenberg PA, Aizenman E. Hundred-fold increase in neuronal vulnerability to glutamate toxicity in astrocyte-poor cultures of rat cerebral cortex. Neurosci Lett 1989;103 (2):162-8.

[55] Bittigau P, Ikonomidou C. Glutamate in neurologic diseases. J Child Neurol 1997;12 (8):471-85.

[56] Amin N, Pearce B. Glutamate toxicity in neuron-enriched and neuron-astrocyte cocultures: effect of the glutamate uptake inhibitor L-trans-pyrrolidine-2,4dicarboxylate. Neurochem Int 1997;30 (3):271-6.

[57] Sheldon AL, Robinson MB. The role of glutamate transporters in neurodegenerative diseases and potential opportunities for intervention. Neurochem Int 2007;51 (67):333-55.

[58] Drejer J, Larsson OM, Schousboe A. Characterization of L-glutamate uptake into and release from astrocytes and neurons cultured from different brain regions. Exp Brain Res 1982;47 (2):259-69.

[59] Takayasu Y, Iino M, Kakegawa W, Maeno H, Watase K, Wada K, Yanagihara D, Miyazaki T, Komine O, Watanabe M, Tanaka K, Ozawa S. Differential roles of glial and neuronal glutamate transporters in Purkinje cell synapses. J Neurosci 2005;25 (38):8788-93.

[60] Slemmer JE, De Zeeuw CI, Weber JT. Don't get too excited: mechanisms of glutamatemediated Purkinje cell death. Prog Brain Res 2005;148:367-90.

[61] Yamashita A, Makita K, Kuroiwa T, Tanaka K. Glutamate transporters GLAST and EAAT4 regulate postischemic Purkinje cell death: an in vivo study using a cardiac arrest model in mice lacking GLAST or EAAT4. Neurosci Res 2006;55 (3):264-70.

[62] Takatsuru Y, Takayasu Y, Iino M, Nikkuni O, Ueda Y, Tanaka K, Ozawa S. Roles of glial glutamate transporters in shaping EPSCs at the climbing fiber-Purkinje cell synapses. Neurosci Res 2006;54 (2):140-8.

[63] Takatsuru Y, Iino M, Tanaka K, Ozawa S. Contribution of glutamate transporter GLT-1 to removal of synaptically released glutamate at climbing fiber-Purkinje cell synapses. Neurosci Lett 2007;420 (1):85-9.

[64] Huang YH, Dykes-Hoberg M, Tanaka K, Rothstein JD, Bergles DE. Climbing fiber activation of EAAT4 transporters and kainate receptors in cerebellar Purkinje cells. J Neurosci 2004;24 (1):103-11.

[65] Fairman WA, Vandenberg RJ, Arriza JL, Kavanaugh MP, Amara SG. An excitatory amino-acid transporter with properties of a ligand-gated chloride channel. Nature 1995;375 (6532):599-603.

[66] Arriza JL, Fairman WA, Wadiche JI, Murdoch GH, Kavanaugh MP, Amara SG. Functional comparisons of three glutamate transporter subtypes cloned from human motor cortex. J Neurosci 1994;14 (9):5559-69.

[67] Hu WH, Walters WM, Xia XM, Karmally SA, Bethea JR. Neuronal glutamate transporter EAAT4 is expressed in astrocytes. Glia 2003;44 (1):13-25.

[68] Furuta A, Martin LJ, Lin CL, Dykes-Hoberg M, Rothstein JD. Cellular and synaptic localization of the neuronal glutamate transporters excitatory amino acid transporter 3 and 4. Neuroscience 1997;81 (4):1031-42.

[69] Tirosh O, Sen CK, Roy S, Packer L. Cellular and mitochondrial changes in glutamateinduced HT4 neuronal cell death. Neuroscience 2000;97 (3):531-41. 
[70] Chen CJ, Liao SL, Kuo JS. Gliotoxic action of glutamate on cultured astrocytes. J Neurochem 2000;75 (4):1557-65.

[71] Patneau DK, Mayer ML. Structure-activity relationships for amino acid transmitter candidates acting at N-methyl-D-aspartate and quisqualate receptors. J Neurosci 1990;10 (7):2385-99.

[72] Camacho A, Massieu L. Role of glutamate transporters in the clearance and release of glutamate during ischemia and its relation to neuronal death. Arch Med Res 2006;37 (1):11-8.

[73] Greenwood SM, Mizielinska SM, Frenguelli BG, Harvey J, Connolly CN. Mitochondrial dysfunction and dendritic beading during neuronal toxicity. J Biol Chem 2007;282 (36):26235-44.

[74] Atterwill CK, Cunningham VJ, Balazs R. Characterization of $\mathrm{Na}+, \mathrm{K}+-\mathrm{ATPase}$ in cultured and separated neuronal and glial cells from rat cerebellum. J Neurochem 1984;43 (1):8-18.

[75] Chih CP, Roberts Jr EL. Energy substrates for neurons during neural activity: a critical review of the astrocyte-neuron lactate shuttle hypothesis. J Cereb Blood Flow Metab 2003;23 (11):1263-81.

[76] Akabayashi A, Kato T. Glucose utilization rates in single neurons and neuropil determined by injecting nontracer amounts of 2-deoxyglucose. J Neurochem 1993;60 (3):931-5.

[77] Itoh Y, Abe T, Takaoka R, Tanahashi N. Fluorometric determination of glucose utilization in neurons in vitro and in vivo. J Cereb Blood Flow Metab 2004;24 (9):993-1003.

[78] Pellerin L, Magistretti PJ. Glutamate uptake into astrocytes stimulates aerobic glycolysis: a mechanism coupling neuronal activity to glucose utilization. Proc Natl Acad Sci U S A 1994;91 (22):10625-9.

[79] Sibson NR, Dhankhar A, Mason GF, Rothman DL, Behar KL, Shulman RG. Stoichiometric coupling of brain glucose metabolism and glutamatergic neuronal activity. Proc Natl Acad Sci U S A 1998;95 (1):316-21.

[80] Shank RP, Campbell GL. Amino acid uptake, content, and metabolism by neuronal and glial enriched cellular fractions from mouse cerebellum. J Neurosci 1984;4 (1):58-69.

[81] Hassel B. Carboxylation and anaplerosis in neurons and glia. Mol Neurobiol 2000;22 (13):21-40.

[82] Hassel B. Pyruvate carboxylation in neurons. J Neurosci Res 2001;66 (5):755-62.

[83] Kato T, Lowry OH. Enzymes of energy-converting systems in individual mammalian nerve cell bodies. J Neurochem 1973;20 (1):151-63.

[84] Dennis SC, Clark JB. The pathway of glutamate metabolism in rat brain mitochondria. Biochem J 1977;168 (3):521-7.

[85] Balazs R. Control of Glutamate Metabolism. The Effect of Pyruvate. J Neurochem 1965;12:63-76.

[86] Yudkoff M, Nissim I, Hummeler K, Medow M, Pleasure D. Utilization of [15N]glutamate by cultured astrocytes. Biochem J 1986;234 (1):185-92.

[87] Sonnewald U, Westergaard N, Schousboe A. Glutamate transport and metabolism in astrocytes. Glia 1997;21 (1):56-63. 
[88] Erecinska M, Zaleska MM, Nissim I, Nelson D, Dagani F, Yudkoff M. Glucose and synaptosomal glutamate metabolism: studies with [15N]glutamate. J Neurochem 1988;51 (3):892-902.

[89] Erecinska M, Silver IA. Metabolism and role of glutamate in mammalian brain. Prog Neurobiol 1990;35 (4):245-96.

[90] McKenna MC, Hopkins IB, Lindauer SL, Bamford P. Aspartate aminotransferase in synaptic and nonsynaptic mitochondria: differential effect of compounds that influence transient hetero-enzyme complex (metabolon) formation. Neurochem Int 2006;48 (6-7):629-36.

[91] Daikhin Y, Yudkoff M. Compartmentation of brain glutamate metabolism in neurons and glia. J Nutr 2000;130 (4S Suppl):1026S-31S.

[92] McKenna MC, Stevenson JH, Huang X, Hopkins IB. Differential distribution of the enzymes glutamate dehydrogenase and aspartate aminotransferase in cortical synaptic mitochondria contributes to metabolic compartmentation in cortical synaptic terminals. Neurochem Int 2000;37 (2-3):229-41.

[93] Wurdig S, Kugler P. Histochemistry of glutamate metabolizing enzymes in the rat cerebellar cortex. Neurosci Lett 1991;130 (2):165-8.

[94] Subbalakshmi GY, Murthy CR. Isolation of astrocytes, neurons, and synaptosomes of rat brain cortex: distribution of enzymes of glutamate metabolism. Neurochem Res 1985;10 (2):239-50.

[95] LaNoue KF, Meijer AJ, Brouwer A. Evidence for electrogenic aspartate transport in rat liver mitochondria. Arch Biochem Biophys 1974;161 (2):544-50.

[96] LaNoue KF, Bryla J, Bassett DJ. Energy-driven aspartate efflux from heart and liver mitochondria. J Biol Chem 1974;249 (23):7514-21.

[97] Balazs R. Control of Glutamate Oxidation in Brain and Liver Mitochondrial Systems. Biochem J 1965;95:497-508.

[98] Berkich DA, Ola MS, Cole J, Sweatt AJ, Hutson SM, LaNoue KF. Mitochondrial transport proteins of the brain. J Neurosci Res 2007;85 (15):3367-77.

[99] Ramos M, del Arco A, Pardo B, Martinez-Serrano A, Martinez-Morales JR, Kobayashi K, Yasuda T, Bogonez E, Bovolenta P, Saheki T, Satrustegui J. Developmental changes in the Ca2+-regulated mitochondrial aspartate-glutamate carrier aralar1 in brain and prominent expression in the spinal cord. Brain Res Dev Brain Res 2003;143 (1):33-46.

[100] Xu Y, Ola MS, Berkich DA, Gardner TW, Barber AJ, Palmieri F, Hutson SM, LaNoue KF. Energy sources for glutamate neurotransmission in the retina: absence of the aspartate/glutamate carrier produces reliance on glycolysis in glia. J Neurochem 2007;101 (1):120-31.

[101] Yudkoff M, Nissim I, Pleasure D. [15N]aspartate metabolism in cultured astrocytes. Studies with gas chromatography-mass spectrometry. Biochem J 1987;241 (1):193201.

[102] Bakken IJ, White LR, Aasly J, Unsgard G, Sonnewald U. [U-13C] aspartate metabolism in cultured cortical astrocytes and cerebellar granule neurons studied by NMR spectroscopy. Glia 1998;23 (3):271-7.

[103] Westergaard N, Drejer J, Schousboe A, Sonnewald U. Evaluation of the importance of transamination versus deamination in astrocytic metabolism of [U-13C]glutamate. Glia 1996;17 (2):160-8. 
[104] Fahien LA, Hsu SL, Kmiotek E. Effect of aspartate on complexes between glutamate dehydrogenase and various aminotransferases. J Biol Chem 1977;252 (4):1250-6.

[105] Fahien LA, Smith SE. The enzyme-enzyme complex of transaminase and glutamate dehydrogenase. J Biol Chem 1974;249 (9):2696-703.

[106] Klockner U, Storck T, Conradt M, Stoffel W. Functional properties and substrate specificity of the cloned L-glutamate/L-aspartate transporter GLAST-1 from rat brain expressed in Xenopus oocytes. J Neurosci 1994;14 (10):5759-65.

[107] Otis TS, Kavanaugh MP. Isolation of current components and partial reaction cycles in the glial glutamate transporter EAAT2. J Neurosci 2000;20 (8):2749-57.

[108] Tretter L, Adam-Vizi V. Generation of reactive oxygen species in the reaction catalyzed by alpha-ketoglutarate dehydrogenase. J Neurosci 2004;24 (36):7771-8.

[109] Geier DA, Geier MR. A clinical and laboratory evaluation of methionine cycletranssulfuration and androgen pathway markers in children with autistic disorders. Horm Res 2006;66 (4):182-8.

[110] Yudkoff M, Nelson D, Daikhin Y, Erecinska M. Tricarboxylic acid cycle in rat brain synaptosomes. Fluxes and interactions with aspartate aminotransferase and malate/aspartate shuttle. J Biol Chem 1994;269 (44):27414-20.

[111] Dringen R. Metabolism and functions of glutathione in brain. Prog Neurobiol 2000;62 (6):649-71.

[112] Pierre K, Pellerin L. Monocarboxylate transporters in the central nervous system: distribution, regulation and function. J Neurochem 2005;94 (1):1-14.

[113] Pow DV. Visualising the activity of the cystine-glutamate antiporter in glial cells using antibodies to aminoadipic acid, a selectively transported substrate. Glia 2001;34 (1):27-38.

[114] Bannai S, Tateishi N. Role of membrane transport in metabolism and function of glutathione in mammals. J Membr Biol 1986;89 (1):1-8.

[115] Raps SP, Lai JC, Hertz L, Cooper AJ. Glutathione is present in high concentrations in cultured astrocytes but not in cultured neurons. Brain Res 1989;493 (2):398-401.

[116] Hertz L, Peng L. Energy metabolism at the cellular level of the CNS. Can J Physiol Pharmacol 1992;70 Suppl:S145-57.

[117] Rimaniol AC, Mialocq P, Clayette P, Dormont D, Gras G. Role of glutamate transporters in the regulation of glutathione levels in human macrophages. Am J Physiol Cell Physiol 2001;281 (6):C1964-70.

[118] Chen Y, Swanson RA. The glutamate transporters EAAT2 and EAAT3 mediate cysteine uptake in cortical neuron cultures. J Neurochem 2003;84 (6):1332-9.

[119] Tan S, Schubert D, Maher P. Oxytosis: A novel form of programmed cell death. Curr Top Med Chem 2001;1 (6):497-506.

[120] Bremer J, Wojtczak AB. Factors controlling the rate of fatty acid -oxidation in rat liver mitochondria. Biochim Biophys Acta 1972;280 (4):515-30.

[121] Pettegrew JW, Levine J, McClure RJ. Acetyl-L-carnitine physical-chemical, metabolic, and therapeutic properties: relevance for its mode of action in Alzheimer's disease and geriatric depression. Mol Psychiatry 2000;5 (6):616-32.

[122] Nalecz KA, Nalecz MJ. Carnitine--a known compound, a novel function in neural cells. Acta Neurobiol Exp (Wars) 1996;56 (2):597-609.

[123] Bremer J. The role of carnitine in intracellular metabolism. J Clin Chem Clin Biochem 1990;28 (5):297-301. 
[124] Bieber LL. Carnitine. Annu Rev Biochem 1988;57:261-83.

[125] Aoyama T, Peters JM, Iritani N, Nakajima T, Furihata K, Hashimoto T, Gonzalez FJ. Altered constitutive expression of fatty acid-metabolizing enzymes in mice lacking the peroxisome proliferator-activated receptor alpha (PPARalpha). J Biol Chem 1998;273 (10):5678-84.

[126] Kondrup J, Lazarow PB. Flux of palmitate through the peroxisomal and mitochondrial beta-oxidation systems in isolated rat hepatocytes. Biochim Biophys Acta 1985;835 (1):147-53.

[127] Bartlett K, Eaton S. Mitochondrial beta-oxidation. Eur J Biochem 2004;271 (3):462-9.

[128] Skorin C, Necochea C, Johow V, Soto U, Grau AM, Bremer J, Leighton F. Peroxisomal fatty acid oxidation and inhibitors of the mitochondrial carnitine palmitoyltransferase I in isolated rat hepatocytes. Biochem J 1992;281 ( Pt 2):561-7.

[129] Hayashi H, Hara M. 1-Alkenyl group of ethanolamine plasmalogen derives mainly from de novo-synthesized fatty alcohol within peroxisomes, but not extraperoxisomal fatty alcohol or fatty acid. J Biochem (Tokyo) 1997;121 (5):978-83.

[130] Hayashi H, Oohashi M. Incorporation of acetyl-CoA generated from peroxisomal betaoxidation into ethanolamine plasmalogen of rat liver. Biochim Biophys Acta 1995;1254 (3):319-25.

[131] Hayashi H, Sato A. Fatty alcohol synthesis accompanied with chain elongation in liver peroxisomes. Biochim Biophys Acta 1997;1346 (1):38-44.

[132] Hayashi H, Takahata S. Role of peroxisomal fatty acyl-CoA beta-oxidation in phospholipid biosynthesis. Arch Biochem Biophys 1991;284 (2):326-31.

[133] Sprecher H, Luthria DL, Mohammed BS, Baykousheva SP. Reevaluation of the pathways for the biosynthesis of polyunsaturated fatty acids. J Lipid Res 1995;36 (12):2471-7.

[134] Reszko AE, Kasumov T, David F, Jobbins KA, Thomas KR, Hoppel CL, Brunengraber $\mathrm{H}$, Des Rosiers C. Peroxisomal fatty acid oxidation is a substantial source of the acetyl moiety of malonyl-CoA in rat heart. J Biol Chem 2004;279 (19):19574-9.

[135] Sliwinski S, Croonenberghs J, Christophe A, Deboutte D, Maes M. Polyunsaturated fatty acids: do they have a role in the pathophysiology of autism? Neuro Endocrinol Lett 2006;27 (4):465-71.

[136] Madiraju P, Pande SV, Prentki M, Madiraju SR. Mitochondrial acetylcarnitine provides acetyl groups for nuclear histone acetylation. Epigenetics 2009;4 (6):399-403.

[137] Lasalle JM, Yasui DH. Evolving role of MeCP2 in Rett syndrome and autism. Epigenomics 2009;1 (1):119-30.

[138] Shahbazian M, Young J, Yuva-Paylor L, Spencer C, Antalffy B, Noebels J, Armstrong $\mathrm{D}$, Paylor R, Zoghbi $\mathrm{H}$. Mice with truncated MeCP2 recapitulate many Rett syndrome features and display hyperacetylation of histone H3. Neuron 2002;35 (2):243-54.

[139] Thatcher KN, LaSalle JM. Dynamic changes in Histone H3 lysine 9 acetylation localization patterns during neuronal maturation require MeCP2. Epigenetics 2006;1 (1):24-31.

[140] Wood PL, Khan MA, Kulow SR, Mahmood SA, Moskal JR. Neurotoxicity of reactive aldehydes: the concept of "aldehyde load" as demonstrated by neuroprotection with hydroxylamines. Brain Res 2006;1095 (1):190-9. 
[141] Dringen R. Oxidative and Antioxidative Potential of Brain Microglial Cells. Antioxidants \& Redox Signaling 2005;7 (9-10):1223-33.

[142] Eichler FS, Ren JQ, Cossoy M, Rietsch AM, Nagpal S, Moser AB, Frosch MP, Ransohoff RM. Is microglial apoptosis an early pathogenic change in cerebral X-linked adrenoleukodystrophy? Ann Neurol 2008;63 (6):729-42.

[143] Brites P, Mooyer PAW, el Mrabet L, Waterham HR, Wanders RJA. Plasmalogens participate in very-long-chain fatty acid-induced pathology. Brain 2009;132:482-92.

[144] Block ML, Hong JS. Microglia and inflammation-mediated neurodegeneration: multiple triggers with a common mechanism. Prog Neurobiol 2005;76 (2):77-98.

[145] Blaylock RL. A possible central mechanism in autism spectrum disorders, part I. Altern Ther Health Med 2008;14 (6):46-53.

[146] Fombonne E. Epidemiology of autistic disorder and other pervasive developmental disorders. J Clin Psychiatry 2005;66 Suppl 10:3-8.

[147] Fombonne E. The epidemiology of autism: a review. Psychol Med 1999;29 (4):769-86.

[148] Ritvo ER, Freeman BJ, Pingree C, Mason-Brothers A, Jorde L, Jenson WR, McMahon WM, Petersen PB, Mo A, Ritvo A. The UCLA-University of Utah epidemiologic survey of autism: prevalence. Am J Psychiatry 1989;146 (2):194-9.

[149] Horlick MB, Rosenbaum M, Nicolson M, Levine LS, Fedun B, Wang J, Pierson RN, Jr., Leibel RL. Effect of puberty on the relationship between circulating leptin and body composition. J Clin Endocrinol Metab 2000;85 (7):2509-18.

[150] Courant F, Aksglaede L, Antignac JP, Monteau F, Sorensen K, Andersson AM, Skakkebaek NE, Juul A, Bizec BL. Assessment of circulating sex steroid levels in prepubertal and pubertal boys and girls by a novel ultrasensitive gas chromatography-tandem mass spectrometry method. J Clin Endocrinol Metab;95 (1):82-92.

[151] Janfaza M, Sherman TI, Larmore KA, Brown-Dawson J, Klein KO. Estradiol levels and secretory dynamics in normal girls and boys as determined by an ultrasensitive bioassay: a 10 year experience. J Pediatr Endocrinol Metab 2006;19 (7):901-9.

[152] Goodman Y, Bruce AJ, Cheng B, Mattson MP. Estrogens attenuate and corticosterone exacerbates excitotoxicity, oxidative injury, and amyloid beta-peptide toxicity in hippocampal neurons. J Neurochem 1996;66 (5):1836-44.

[153] Harms C, Lautenschlager M, Bergk A, Katchanov J, Freyer D, Kapinya K, Herwig U, Megow D, Dirnagl U, Weber JR, Hortnagl H. Differential mechanisms of neuroprotection by 17 beta-estradiol in apoptotic versus necrotic neurodegeneration. J Neurosci 2001;21 (8):2600-9.

[154] Hilton GD, Ndubuizu AN, McCarthy MM. Neuroprotective effects of estradiol in newborn female rat hippocampus. Brain Res Dev Brain Res 2004;150 (2):191-8.

[155] McClean J, Nuñez JL. 17alpha-Estradiol is neuroprotective in male and female rats in a model of early brain injury. Exp Neurol 2008;210 (1):41-50.

[156] Mendelowitsch A, Ritz MF, Ros J, Langemann H, Gratzl O. 17beta-Estradiol reduces cortical lesion size in the glutamate excitotoxicity model by enhancing extracellular lactate: a new neuroprotective pathway. Brain Res 2001;901 (1-2):230-6.

[157] Nilsen J, Diaz Brinton R. Mechanism of estrogen-mediated neuroprotection: regulation of mitochondrial calcium and Bcl-2 expression. Proc Natl Acad Sci U S A 2003;100 (5):2842-7. 
[158] Singer CA, Rogers KL, Strickland TM, Dorsa DM. Estrogen protects primary cortical neurons from glutamate toxicity. Neurosci Lett 1996;212 (1):13-6.

[159] Vavaiya KV, Briski KP. Effects of caudal hindbrain lactate infusion on insulin-induced hypoglycemia and neuronal substrate transporter glucokinase and sulfonylurea receptor-1 gene expression in the ovariectomized female rat dorsal vagal complex: Impact of estradiol. J Neurosci Res 2008;86 (3):694-701.

[160] Zhang Y, Lu X, Bhavnani BR. Equine estrogens differentially inhibit DNA fragmentation induced by glutamate in neuronal cells by modulation of regulatory proteins involved in programmed cell death. BMC Neurosci 2003;4:32.

[161] Klein KO, Baron J, Colli MJ, McDonnell DP, Cutler GB, Jr. Estrogen levels in childhood determined by an ultrasensitive recombinant cell bioassay. J Clin Invest 1994;94 (6):2475-80.

[162] Simpkins JW, Wang J, Wang X, Perez E, Prokai L, Dykens JA. Mitochondria play a central role in estrogen-induced neuroprotection. Curr Drug Targets CNS Neurol Disord 2005;4 (1):69-83.

[163] Simpkins JW, Yi KD, Yang SH, Dykens JA. Mitochondrial mechanisms of estrogen neuroprotection. Biochim Biophys Acta 2010;1800 (10):1113-20.

[164] Prokai L, Prokai-Tatrai K, Perjesi P, Zharikova AD, Perez EJ, Liu R, Simpkins JW. Quinol-based cyclic antioxidant mechanism in estrogen neuroprotection. Proc Natl Acad Sci U S A 2003;100 (20):11741-6.

[165] Djouadi F, Weinheimer CJ, Saffitz JE, Pitchford C, Bastin J, Gonzalez FJ, Kelly DP. A gender-related defect in lipid metabolism and glucose homeostasis in peroxisome proliferator- activated receptor alpha- deficient mice. J Clin Invest 1998;102 (6):1083-91.

[166] Maher KR, Harper JF, Macleay A, King MG. Peculiarities in the endocrine response to insulin stress in early infantile autism. J Nerv Ment Dis 1975;161 (3):180-4.

[167] Nagy I, Hirka G, Kurcz M, Anda E, Baranyai P. The role of estrogens in the regulation of lactate dehydrogenase activity and its submolecular organization in rat anterior pituitary. Endokrinologie 1978;71 (1):1-12.

[168] Mandour T, Kissebah AH, Wynn V. Mechanism of oestrogen and progesterone effects on lipid and carbohydrate metabolism: alteration in the insulin: glucagon molar ratio and hepatic enzyme activity. Eur J Clin Invest 1977;7 (3):181-7.

[169] Courchesne E, Redcay E, Kennedy DP. The autistic brain: birth through adulthood. Curr Opin Neurol 2004;17 (4):489-96.

[170] Courchesne E, Saitoh O, Yeung-Courchesne R, Press GA, Lincoln AJ, Haas RH, Schreibman L. Abnormality of cerebellar vermian lobules VI and VII in patients with infantile autism: identification of hypoplastic and hyperplastic subgroups with MR imaging. AJR Am J Roentgenol 1994;162 (1):123-30.

[171] Herbert MR, Ziegler DA, Makris N, Filipek PA, Kemper TL, Normandin JJ, Sanders HA, Kennedy DN, Caviness VS, Jr. Localization of white matter volume increase in autism and developmental language disorder. Ann Neurol 2004;55 (4):530-40.

[172] Schneider GH, Baethmann A, Kempski O. Mechanisms of glial swelling induced by glutamate. Can J Physiol Pharmacol 1992;70 Suppl:S334-43.

[173] Canitano R. Epilepsy in autism spectrum disorders. Eur Child Adolesc Psychiatry 2007;16 (1):61-6. 
[174] Devi PU, Manocha A, Vohora D. Seizures, antiepileptics, antioxidants and oxidative stress: an insight for researchers. Expert Opin Pharmacother 2008;9 (18):3169-77.

[175] Waldbaum S, Patel M. Mitochondrial dysfunction and oxidative stress: a contributing link to acquired epilepsy? J Bioenerg Biomembr 2010;42 (6):449-55.

[176] Gargus JJ. Genetic calcium signaling abnormalities in the central nervous system: seizures, migraine, and autism. Ann N Y Acad Sci. 2009;1151:133-56.

[177] Palmieri F. Diseases caused by defects of mitochondrial carriers: a review. Biochim Biophys Acta 2008;1777 (7-8):564-78.

[178] Chen SD, Chang AY, Chuang YC. The potential role of mitochondrial dysfunction in seizure-associated cell death in the hippocampus and epileptogenesis. J Bioenerg Biomembr 2010;42 (6):461-5.

[179] Ashwin E, Ashwin C, Rhydderch D, Howells J, Baron-Cohen S. Eagle-eyed visual acuity: an experimental investigation of enhanced perception in autism. Biol Psychiatry 2009;65 (1):17-21.

[180] Simmons DR, Robertson AE, McKay LS, Toal E, McAleer P, Pollick FE. Vision in autism spectrum disorders. Vision Res 2009;49 (22):2705-39.

[181] Birch EE, Carlson SE, Hoffman DR, Fitzgerald-Gustafson K, Fu VL, Drover JR, Castañeda YS, Minns L, Wheaton DK, Mundy D, Marunycz J, Diersen-Schade DA. The DIAMOND (DHA Intake And Measurement Of Neural Development) Study: a double-masked, randomized controlled clinical trial of the maturation of infant visual acuity as a function of the dietary level of docosahexaenoic acid. Am J Clin Nutr 2010;91 (4):848-59.

[182] Jacques C, Levy E, Muckle G, Jacobson SW, Bastien C, Dewailly E, Ayotte P, Jacobson JL, Saint-Amour D. Long-term effects of prenatal omega-3 fatty acid intake on visual function in school-age children. J Pediatr 2011;158 (1):83-90. 


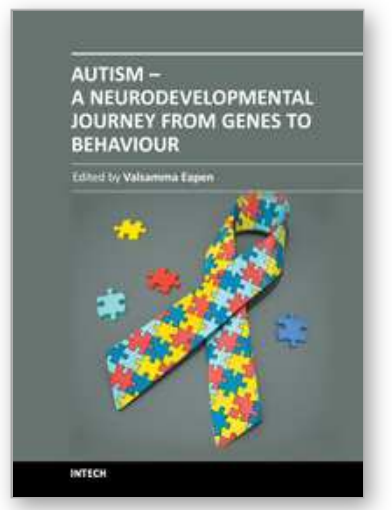

\author{
Autism - A Neurodevelopmental Journey from Genes to Behaviour \\ Edited by Dr. Valsamma Eapen
}

ISBN 978-953-307-493-1

Hard cover, 484 pages

Publisher InTech

Published online 17, August, 2011

Published in print edition August, 2011

The book covers some of the key research developments in autism and brings together the current state of evidence on the neurobiologic understanding of this intriguing disorder. The pathogenetic mechanisms are explored by contributors from diverse perspectives including genetics, neuroimaging, neuroanatomy, neurophysiology, neurochemistry, neuroimmunology, neuroendocrinology, functional organization of the brain and clinical applications from the role of diet to vaccines. It is hoped that understanding these interconnected neurobiological systems, the programming of which is genetically modulated during neurodevelopment and mediated through a range of neuropeptides and interacting neurotransmitter systems, would no doubt assist in developing interventions that accommodate the way the brains of individuals with autism function. In keeping with the multimodal and diverse origins of the disorder, a wide range of topics is covered and these include genetic underpinnings and environmental modulation leading to epigenetic changes in the aetiology; neural substrates, potential biomarkers and endophenotypes that underlie clinical characteristics; as well as neurochemical pathways and pathophysiological mechanisms that pave the way for therapeutic interventions.

\title{
How to reference
}

In order to correctly reference this scholarly work, feel free to copy and paste the following:

Dayan Goodenowe and Elodie Pastural (2011). The Biochemical Basis of Autistic Behavior and Pathology, Autism - A Neurodevelopmental Journey from Genes to Behaviour, Dr. Valsamma Eapen (Ed.), ISBN: 978953-307-493-1, InTech, Available from: http://www.intechopen.com/books/autism-a-neurodevelopmentaljourney-from-genes-to-behaviour/the-biochemical-basis-of-autistic-behavior-and-pathology

\section{INTECH}

open science | open minds

\section{InTech Europe}

University Campus STeP Ri

Slavka Krautzeka 83/A

51000 Rijeka, Croatia

Phone: +385 (51) 770447

Fax: +385 (51) 686166

www.intechopen.com

\section{InTech China}

Unit 405, Office Block, Hotel Equatorial Shanghai

No.65, Yan An Road (West), Shanghai, 200040, China 中国上海市延安西路65号上海国际贵都大饭店办公楼 405 单元

Phone: +86-21-62489820

Fax: $+86-21-62489821$ 
(C) 2011 The Author(s). Licensee IntechOpen. This chapter is distributed under the terms of the Creative Commons Attribution-NonCommercialShareAlike-3.0 License, which permits use, distribution and reproduction for non-commercial purposes, provided the original is properly cited and derivative works building on this content are distributed under the same license. 